\title{
Profile-oriented programming teaching to non technical students: A case study
}

\author{
Fernando Moreira \\ IJP, UPT, Porto, Portugal \\ IEETA, UA, Aveiro, \\ Portugal \\ fmoreira@upt.pt
}

\author{
Maria João Ferreira \\ UPT, DEGI, Porto, Portugal \\ ISTTOS, Algoritmi, UM, \\ Braga, Portugal \\ mjoao@upt.pt
}

\author{
Cesar A. Collazos \\ University of Cauca, \\ Colombia \\ ccollazo@unicauca.edu.co
}

\author{
Sandra Cano \\ University of San \\ Buenaventura, Colombia \\ sandra.cano@gmail.com
}

\begin{abstract}
Programming education has been one of the most complex tasks in higher education over the years. One of the great difficulties that students face when they start a curricular unit linked to programming is to acquire skills which allow them solving real life problems through the use of algorithms. Such skills require the development of the ability to abstract as well as to apply algorithms development techniques. These difficulties are even greater when students attend to a course that does not have as main objective the programming of computers and their basic education is on non-technological areas. As a result of the difficulty in obtaining these competences, there are high failure and dropout rates in courses related to this study field. In order to solve this problem, we propose a methodology based on VARK questionnaire and students background to define the students' profile and, consequently, define what are the appropriate educational materials and tools. To validate this model, a pilot experiment with students to be divided into two groups was carried out, in the academic year 2015-2016, with the application of the model to one of them. In the end, it was found that the final results obtained in the group where the proposed methodology was applied were superior.
\end{abstract}

Keywords - algorithms; programms; VARK questionnaire; methodology; instructional materials; didactic tools.

\section{INTRODUCTION}

The teaching of programming has been over the years, one of the more complex tasks in higher education. The abstraction necessary for the interpretation of the problems and the systematization of the resolution is complex and one of the biggest challenges proposed to students and the more problematic. As evidenced by the high rates of disapproval in curricular units (CU) for these themes [1], [2]. This problem is aggravated when this type of $\mathrm{CU}$ is taught in courses not designed for students whose education is not technological areas. In this context arises the need to introduce more attractive methodologies and to present real-world problems [20]. As Dewey suggests [3] in order to minimize the problem. This author suggests that students should be confronted with real-life problems and teachers, or the couple, should assist in search of the necessary information for your resolution.

In order to improve the results of students in UC related to algorithms and programming, they need to interact with the learning environment through all sensory directions, i.e., speaking, listening, reading, writing, as well as to experience and think about their own knowledge when attending the course content [4]. Active learning theories make teachers and students to actively participate in their learning environment in order to explore, experiment, test and apply the knowledge acquired in the classroom to solve real-life problems, as the main goal of algorithms development [5].

The goal of the research is to contribute to the improvement of the teaching-learning process of CUs in the area of algorithms and programming. In this paper, a case study applying an adapted version of the model [6] to the CU "Introduction to Algorithms" is presented, of a graduation course where the students come from completely different areas of the said course area.

The rest of the paper is organized as follows. In the next section, a background of the addressed subjects is presented. The research methodology is described in the section III. In sections IV and V it is presented the methodology and the case study. Finally, in the last section, conclusions are discussed.

\section{BACKGROUND}

\section{A. Relationship between Bloom's Taxonomy and algorithms/ programming}

The selection of tools for the construction of algorithms and/or programs to be used in the CUs where students are required to create products, i.e. algorithms and/or software programs, needs to take into account a theoretical framework that allows to make an appropriate selection and adoption these same tools. According to Krathwohl [7] the use of Bloom's Taxonomy appears as the most adequate. The Bloom's Taxonomy [7] is characterized by defining a set of educational goals and objectives. Thus, in this referred framework are presented the objectives and the respective processes and resulting learning. The author describes a set of thinking capacities, beginning with the lower-order thinking capacities, which form the basis of a hierarchy and which terminates in higher order thinking capacities. Cheong, et al. [8] presents Bloom's Taxonomy with the following classification: Remembering, Understanding, Applying, Analyzing, Evaluating and Creating, where each level has a set of verbs to be used in the definition of learning objectives to be achieved by students. 
This taxonomy is shown graphically in Figure 1.

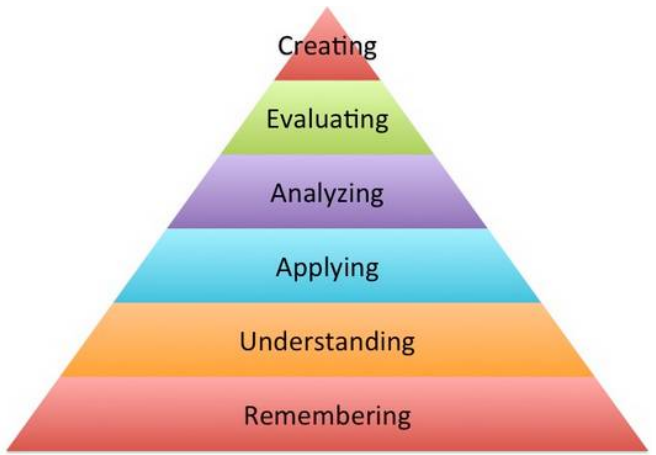

Figure 1. The new version of Bloom's Taxonomy ${ }^{1}$

TABLE I. RELATION BETWEEN BLOOM TAXONOMY AND ALGORITMS/ PROGRAMMING LEARNING

\begin{tabular}{|c|c|c|}
\hline & $\begin{array}{l}\text { Tasks in the development of algorithms } \\
\text { and programs }\end{array}$ & Skill \\
\hline \multirow{8}{*}{ 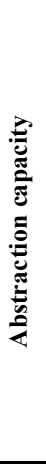 } & Recognize the syntax of an instruction. & \multirow{2}{*}{ H1. Remember } \\
\hline & Recognize the semantics of an instruction. & \\
\hline & $\begin{array}{l}\text { Interpret what changes occur when } \\
\text { modifying an instruction. }\end{array}$ & \multirow{3}{*}{ H2. Understand } \\
\hline & $\begin{array}{l}\text { Translate an algorithm by providing the } \\
\text { pseudocode or a flowchart. }\end{array}$ & \\
\hline & $\begin{array}{l}\text { Translate an algorithm on a programming } \\
\text { language. }\end{array}$ & \\
\hline & $\begin{array}{l}\text { Use structures with a definite and clear } \\
\text { purpose (decisions, cycles). }\end{array}$ & \multirow{3}{*}{$\begin{array}{l}\text { H3. Abstract/ } \\
\text { Apply }\end{array}$} \\
\hline & $\begin{array}{l}\text { Use functions/methods/routines to perform } \\
\text { a specific task. }\end{array}$ & \\
\hline & Modify an algorithm or program. & \\
\hline \multirow{8}{*}{ 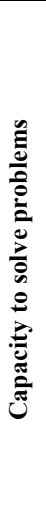 } & $\begin{array}{l}\text { Predict the possible effects on running a } \\
\text { line-by-line algorithm. }\end{array}$ & \multirow{2}{*}{ H4. Analyze } \\
\hline & $\begin{array}{l}\text { Detect possible errors in an algorithm or } \\
\text { program. }\end{array}$ & \\
\hline & $\begin{array}{l}\text { Evaluate requirements at the level of the } \\
\text { user, system, organization and develop a } \\
\text { coherent algorithmic solution so that it is } \\
\text { possible to code in a program. }\end{array}$ & \multirow{3}{*}{$\begin{array}{l}\text { H5. Prove / } \\
\text { Evaluate }\end{array}$} \\
\hline & $\begin{array}{l}\text { Compare algorithmic solutions or } \\
\text { programs that solve the same problem. }\end{array}$ & \\
\hline & Check a set of instructions through tests. & \\
\hline & $\begin{array}{l}\text { Generate a complete algorithm from the } \\
\text { specifications of a problem. }\end{array}$ & \multirow{3}{*}{$\begin{array}{l}\text { H6. Model / } \\
\text { Formalize / Create }\end{array}$} \\
\hline & $\begin{array}{l}\text { Generate a complete program from the } \\
\text { algorithm produced. }\end{array}$ & \\
\hline & Generalize an algorithm. & \\
\hline
\end{tabular}

The current version of Bloom's Taxonomy presents six levels (Figure 1) that have, as referred, different objectives: (i) Retrieving relevant knowledge from long-term memory. (ii) Determining the meaning of instructional messages, including oral, written, and graphic communication. (iii) Carrying out or using a procedure in a given situation. (iv) Breaking material into its constituent parts and detecting how the parts relate to one another and to an overall structure or purpose. (v) Making judgments based on criteria. (vi) Putting elements together to form a novel, coherent whole or make an original product.

In this context, in addition to the referential, it is necessary to analyze/select the learning theory(ies) that best adapt to the teaching of algorithms and programming. In the proposed teaching learning approach is used the cognitive theory and the instructional theory of Gagné. According to the author "The student has to know how to manipulate a language and other symbols to know new things, what is possible for the activation of strategies that facilitate learning and its permanence in memory" [9]. In addition to the presented above, a Computational Thinking test [10] was also used to identify students' levels of algorithmic competences, which are fundamental for programming. Table I shows the desired capacities and the respective competences developed according to the taxonomy of Bloom (Figure 1).

\section{B. Learning styles}

The teaching process presents two important facets that together allow lead to success: (1) premeditated and (2) organized actions. This process can be translated into an activity where the teacher should use the appropriate methods, with the aim to lead the student to develop their skills. The process can be translated into an activity where the teacher must use the appropriate methods, with the aim to lead the student to develop their skills. It is a dynamic development where the student is in a constant activity, which benefits of maturity, being a result of individual experience.

The speed and the way that students assimilate new information and ideas, as well as the process and use them varies considerably from student to student, making it clear that there are individual learning styles. In this context, Coffield et al. [11] questioned whether the existence of learning problems would be related to the difficulties that students have in capturing, assimilating and storing what is past, or if the way in which teachers transmit the information is preventing effective learning.

Meet the learning style of each student is important since it allows you to adjust the models profiles education found. To obtain this kind of results, are needed tools that combine how students learn and, scales that quantify how new information is received and processed by them [12], [21]. The classification analyses the meanings by which a student assimilates content in the classroom (senses such as hearing, sight and touch / experimentation), and the scales measure the proportion with which each is used. In [12] the importance of navigating the learning styles is discussed, as well as methods that teachers can adopt to reach all types of students, because each one learns in a proper and individualized way.

VARK - Visual (V), Aural (A), Read / Write (R) e Kinaesthetic (K) [13] is a method that allows to measure learning styles and is based on the thought that for the learning styles to the applied contents is a task too arduous for the teachers. The breadth of styles and dimensions is huge, and the possible combinations in a group of students are extensive. [13]

\footnotetext{
${ }^{1}$ http://ii.library.jhu.edu/2015/01/30/a-guide-to-blooms-taxonomy/
} 
is a method that allows to measure learning styles and is based on the thought that for the learning styles to the applied contents is a task too arduous for the teachers. Their conclusion was that the most appropriate way to to address the issue is to provide the students themselves with knowledge about their individual learning style, so that they can learn to adapt according to the situation that they are experiencing.

Based on the model, there is the VARK (http://www.varklearn.com) questionnaire instrument, which consists of 16 multiple choice questions, and can be checked more than one alternative. At the end of accomplishment and a test is assigned a classification and is identified the respondent preferred learning mode (student). For example, students (V) prefer maps, tables, charts, diagrams, brochures, flowcharts, images and varied spatial arrangements. Students (A) like to explain ideas, discuss topics, attend lectures and learn from stories. The (R) learn best using lists, tests, reports, text books, printed brochures, lectures, definitions, manuals and web pages. Finally, students (K) learn by trial and error, like field trips and also to try to understand [14].

\section{RESEARCH METHODOLOGY}

\section{A. The study hypotheses and research methodology}

The research methodology can be defined as a collection of tests and analysis approach that can be used to understand a phenomenon that contributes to the body of knowledge [15].

The educational objectives, pedagogical models, student characteristics, strategies and instructional technologies that best fit the expectations of the participants in the teaching-learning process (teacher, students and Educational context) were considered in order to create the curricular unit "Introduction to Algorithm". Regarding the instructional model, we chose the model developed in [6], with an adjustment considered essential and presented in the following section. The statement "integration by objectives" reinforces the importance of integrating technologies in the educational context, supported by the learning objectives established for the curricular unit referenced above. This approach aims to intensify the importance of learning objectives in the design and implementation of learning activities.

Two study hypotheses were set in order to understand the proposed methodology: (1) Can students with a profile obtained by VARK questionnaire and prior knowledge perform better when are used oriented materials and tools?; (2) It is possible to develop materials for a group whose profiles are heterogeneous or in a group whose students have a predominant profile according to the results obtained from questionnaire VARK?

The obtained results will be based on a research technique that makes use of pre and post-tests that measure the knowledge acquired by students in a learning activity. Such tests consist on the application of a set of questions that must be answered by students before and after a particular activity. In particular, the pre-test allows determining the level of knowledge of participants on an issue that will be approached before training. The post-test consists in applying a set of questions with the same level of difficulty, in order to assess the evolution of the acquired skills [16].
In this project were created two different groups of students who were part of the study. The first group $(n=24)$, or control group, had a similar education to that of the previous year, i.e. without the application of the developed model. In the second group $(\mathrm{m}=24)$, the model developed in [6] was applied, with the adaptations presented in the next section. The course contents, learning objectives and teachers were the same. The classifications of the group assignments in conjunction with the final exam scores were used to make more objective comparisons/analyzes. The available contents were developed with free access tools, some study and consultation materials were made available, for example, from videos published on YouTube, etc., while the programming tools used were chosen with the aim of going to Meeting the profile of this type of student. The articulation of contents with learning objectives, teaching strategies and assessment techniques was given close attention so that, as a whole, they could provide a relevant and meaningful learning experience.

The obtained results (project and final exam grades) will be used to measure the knowledge acquired by students in the learning activities, and consequently, lead to a decrease in failure and dropout rates. Furthermore, it should also contribute to the identification of the gaps present in the teaching-learning process regarding students that hold no predominant profile.

\section{PROPOSED METHODOLOGY}

In general, we can state that teachers should consider the learning styles of students while designing and throughout the development of UCs. Despite the fact that it may not be highly essential for teachers to test and instruct students in all situations, testing them with the VARK instrument - simple and fast - can provide important information to create an effective learning environment. Additionally, analyses of the students' background regarding the content that will be taught in the course unit were part of the initial stage. To be aware of learning styles and considering its impact on the learning environments are the first steps towards an essential understanding of the profile of the students when developing a UC to teach algorithms.

\section{A. Methodology}

As discussed previously it is important to define the students profile and their prior knowledge in order to help to select the right tools and design and development of teaching materials. With this assumption a methodology is proposed. It consists of five different components with a defined sequence (Figure 2).

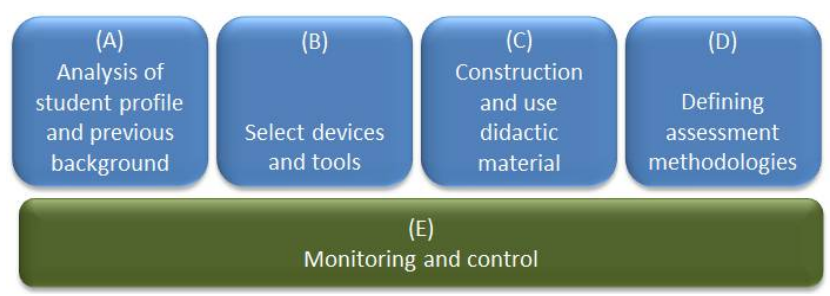

Figure 2. Methodology components.

In the component (A) Both the VARK questionnaire and background study is used to analyze and define the students' profile who attend UC Introduction to Algorithms in order to 
understand what kind of devices and tools will be used, if the model is applied to classroom teaching, distance learning (elearning), blended learning (b-learning), or to be used only in mobile devices (mobile learning, m-learning) (B). Once it has chosen the teaching model, it will be defined which materials to use or build from scratch (for instance, if those materials should be more descriptive or visual, etc.) (C). For instance, the use of e-learning or m-learning involves the production of materials appropriate for such type of devices. Some of the most important components in the teaching-learning models are the used assessment methodologies (D). The whole methodology has a monitoring and control process (E) which allows the adjustment of the materials, devices used and assessment methodology, as long as students and teachers understand these needs.

\section{CASE STUdy}

\section{A. Analysis of student profile and background}

In this subsection the results of the responses to the student background surveys as well as their learning styles will be analysed after the VARK questionnaire response.

\section{Characterization of the sample}

Twenty-four students were selected for the test group and, 24 for the control group, from a Humanities Degree, at a higher education institution, in the second semester of the 2015-2016 school year. All students answered, in the first class, the inquiry related to their background in three different dimensions: I General information with two questions; II - General information on the use of ICT, with 7 questions and III Experience in the programming of computers with 13 questions.

\section{Results analysis - Characterization of the sample}

There were 24 respondents in total, corresponding to $100 \%$ of the total number of students enrolled in the course unit. The results presented will be greatly reduced due to the limited number of pages. Regarding dimension I, it was found that $32 \%$ of the students are male and 68\% female. Among them, $77 \%$ were under 21 years of age, $14 \%$ between 21 and $24,5 \%$ between 25 and $29,5 \%$ between 30 and 35 and $0 \%$ over 35 years.

For dimension II only the results concerning the questions "Assign a classification to your competences in the use of the computer" and "Have you some programming experience?" Will be presented. Regarding the first question it is possible to observe (figure 3 ) that $68 \%$ has competencies from the user's point of view. As for the second question, it was found that only 6 students, three in each group, had some programming experience.

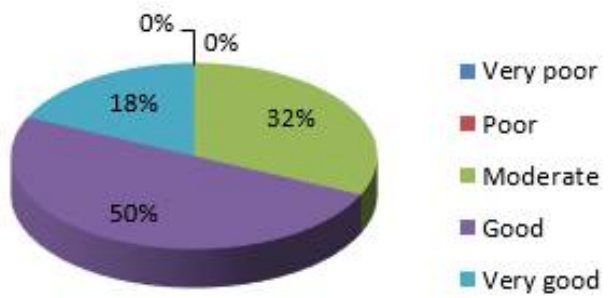

Figure 3. Results to the question "Assign a classification to your competences in the use of the computer"
Dimension III was intended for students who had responded positively to the question "Do you have any programming experience?" of dimension II. As previously indicated only 6 students replied that they had programming experience.

In this dimension, the answers to two questions that adequately characterize $27 \%$ of the students regarding programming experience are also presented.

The first question is "Choose the designation that best describes your level of experience in each of the programming languages.", and the second is "Choose the designation that best describes your understanding of the following programming topics".

In the analysis of the first question it is verified (Figure 4) that there are languages that the students had no knowledge of (Kodu; Scratch; Pythen; Perl; C), while in most others (Java, C, ...) knowledge was very small.

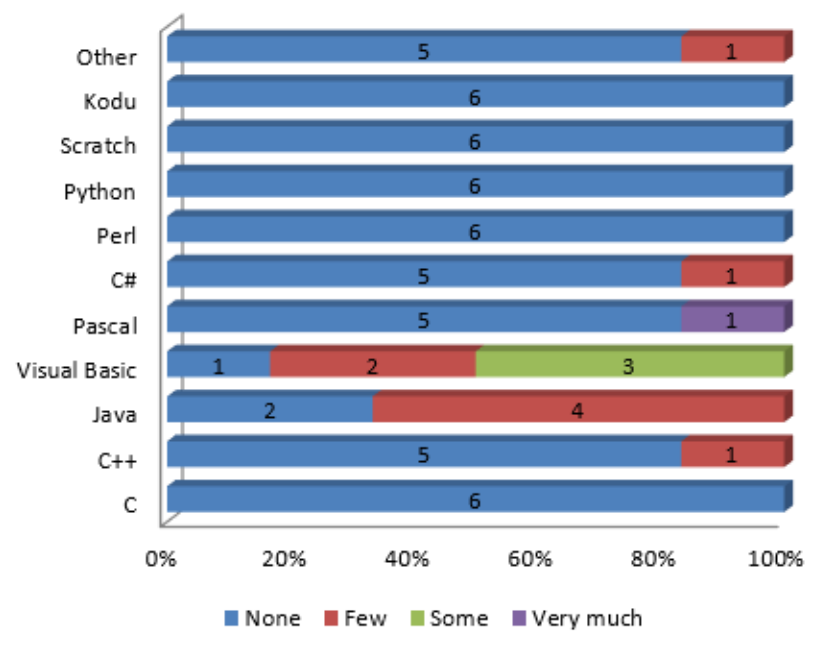

Figure 4. Results to the question "Choose the designation that best describes your level of experience in each of the programming languages.".

In the analysis of the second question "Choose the designation that best describes your understanding of the following programming topics" is verified (figure 5), that the knowledge on these topics is practically non-existent.

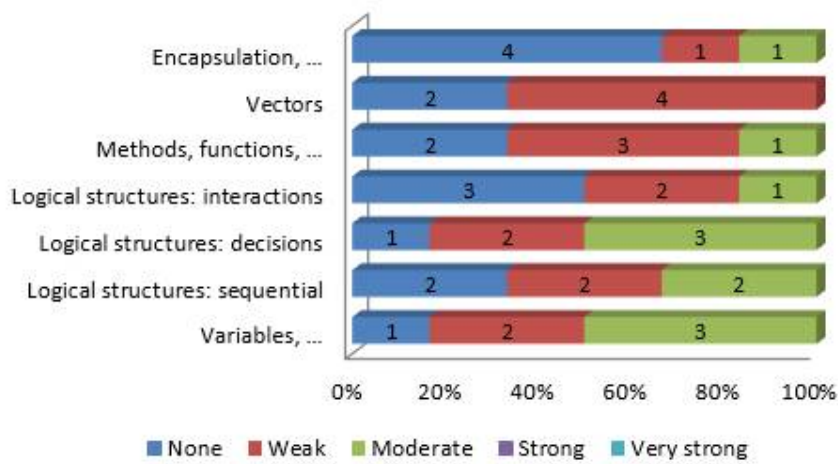

Figure 5. Results to the question "Choose the designation that best describes your understanding of the following programming topics.". 


\section{Results of the VARK Questionnaire}

In the universe of the 24 students who answered the VARK questionnaire, $50 \%$ were classified as predominantly Kinaesthetic, that is, those who make constant use of tact and experimentation to absorb new contents. The second most frequent classification was predominantly Aural/Kinaesthetic and Aural with 14\%, respectively. The number of students with characteristics that fit the other styles are residual, as can be seen in the graph of figure 6 .

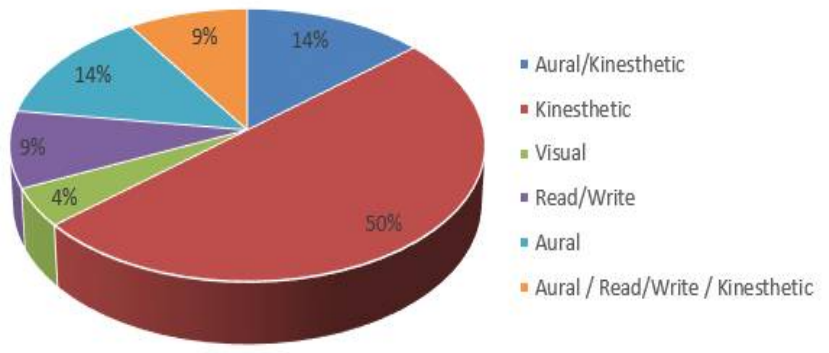

Figure 6. Results of the VARK Questionnaire .

\section{B. Select devices and tools}

The selection of devices was easy because students chose the use of personal and portable computers over the use of mobile devices (smartphones and tablets), because they feel more comfortable.

The choice of tools took into account two assumptions, the students attending a non-technological course, and the lack of previous knowledge regarding the programming area, as discussed previously. In this context, and based on a study presented in [17], two tools were chosen according to the curricular unit program. The first part is directly related to the development of abstract thinking and to achieve this goal is taught the development of algorithms. In order to allow a more practical approximation to the thematic one was used Portugol IDE [18] that presents / displays a graphical interface of interaction and a language almost equal to the algorithmic language. In the second part of the curricular unit the objective is focused on the teaching of a programming language. Thus, it was necessary to take into account both the background of the students and the profile of the course. In this phase the language chosen was Scratch [19] for its graphic character, it is possible to be executed in almost all the operating systems, it is a language Block or Bubble Languages and it is considered for Beginners.

\section{Construction of didatic material}

The construction of didactic material was relatively easy due to the high number of materials, to these areas, available in free access. Taking into account the results obtained in subsection $\mathrm{A}$ of section $\mathrm{V}$, video tutorials, also known as podcasting, were used. The teacher can record the lesson/session and make it available in the Internet if shared openly at YouTube or more restrictively in the LMS platform. The class "Programming logic with Scratch - Class 5" (https://www.youtube.com/watch? $\mathrm{v}=\mathrm{YcOuRO}$ GYuA) is an example of the shared distribution of high quality content. In this context students can follow the lesson/session outside the classroom and use class time/session to explore some other concepts in more detail.

All the videos provided were complemented with the projection and explanation of the theoretical concepts, as well as the accomplishment, together, of some examples of algorithms and programs before the exercises resolution by the students.

The exercises available, on the institution's LMS platform, were developed in order to meet the programmatic contents following a difficulty order according to the students' progress in their knowledge and particularly in solving problems.

\section{Assessment methodologies}

The evaluation methodology initially designed for this curricular unit had a diverse set of tools that would be used (e.g. Quizzes), but it was verified that the structure of the curricular unit and the type of students required a more practical application, it was necessary to adapt the evaluation methodology.

As stated above, the programmatic content is mostly practical. In this context, exercises were carried out in all the classes, with the teacher monization, in order to perceive the progression in learning in each activity. As this type of assessment was not formally defined initially, it was mandatory to carry out a group work, with presentation and a final exam. For the definition of the groups were asked to students to organize themselves in groups of two in order to be easier to keep track of what each has developed. The evaluation based on the group work, as referred, forced the students to make a public presentation of the work, as well as an individual discussion about the project. The final exam was used to make the individual assessment of each student and to complement the evaluation made on the basis of group work.

\section{E. Results}

The results presented are related to the final grades, of the two groups (Test or Research and Control), that students obtained at the end of the semester. These results are the evaluation compilation of the final results period - Distributed, Normal, Resource and Special.

The Figure 7 presents a comparative final results, with the abscissa axis to represent the grades ( 0 to 20), and the ordinates axis the number of students that have obtained a certain grade. From the final results analysis (figure 7) it is possible to highlight some interesting points. However, it is also necessary to indicate that the results obtained with the research group were not, in this first experiment, significantly superior to those of the control group. 


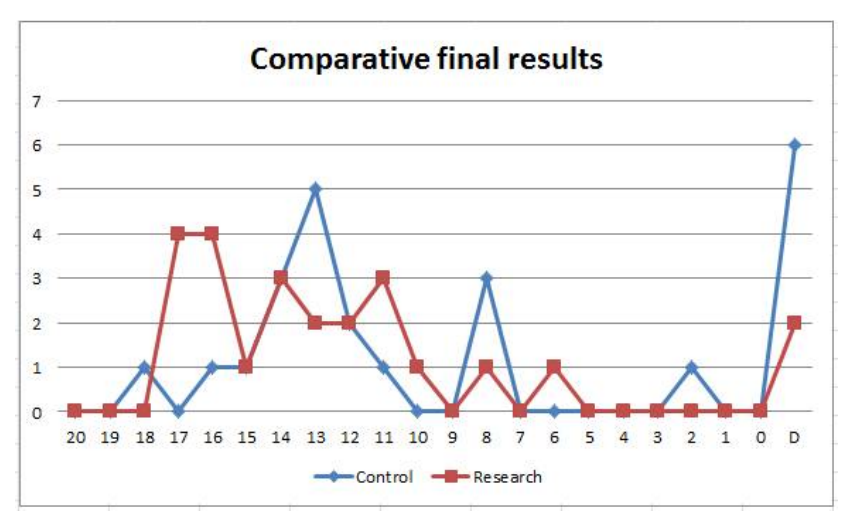

Figure 7. Comparative final results.

From the analysis of results it is possible to observe some interesting values that allow us to believe in the added value that this model has in the teaching-learning process, in this case in curricular units linked to algorithm and programming.

TABLE II. RESULTS FOR BOTH GROUPS

\begin{tabular}{|l|c|c|c|}
\hline & Approved & Failure & Dropout \\
\hline Control & 14 & 4 & 6 \\
Research & 20 & 2 & 2 \\
\hline
\end{tabular}

The combination of the values presented in both, figure 7 and Table II, shows that the number of approved students was $83 \%$ in the research group and only $58 \%$ in the control group. Thus, the failure rate decreased compared to previous years. Additionally, another of the positive results was the reduction in the number of dropout students, since the number for the research group was 2 and in the control group it was 6 , that is, $8 \%$ and $25 \%$, respectively.

\section{CONCLUSIONS}

One of the major challenges in the definition of courses directed to the programming of computers (algorithms and implementation in a programming language) concerns the definition of methodologies that allow to reduce the high failure and dropout rates of students. This challenge deserves special attention when students are from non-technical areas and the courses are not directly related to computer science or computer science.

In this way and in order to minimize the problems related to the high failure and dropout rates of students, a methodology was proposed based on VARK questionnaire and students background to define their profile and consequently, to define the materials and tools more appropriate to teach algorithms and programming languages.

It is intended, in this research, to continue testing the proposed methodology, introducing improvements in the type of materials available, in the evaluation process (introduction of several phases, namely, in a first phase, peer evaluation within the group, in a second phase a Peer evaluation of different groups and a third phase the evaluation from teachers), and the way in which students are monitored may be trough the introduction of more collaborative models.

\section{REFERENCES}

[1] A. Engelbrecht, P. Dilermando, G. Nakamiti, F. Bianchi, "Algoritmos e Programação de Computadores.”, Editora Campus, São Paulo, 2012.

[2] A. Gomes, J. Henriques, A. Mendes, "Uma proposta para ajudar alunos com dificuldades na aprendizagem inicial de programação de computadores" Educação, Formação e Tecnologia, 1, 2008, pp. 93-103.

[3] J. Dewey, Democracy And Education. New York: Free Press, 1997.

[4] C. Meyers, T. Jones, "Promoting Active Learning: Strategies for the College Classroom", Jossey-Bass, 1993.

[5] W. Longmire, “A Primer on Learning Objects". IN Circuits, A. L. (Ed.), ASTD Learning Circuits. 2000.

[6] F. Moreira, M. J. Ferreira,. "Profile-oriented algorithms teaching: a proposed methodology," In Proceedings of the 10th Iberian Conference on Information Systems and Technologies (CISTI), Vol 2, pp 43-46, 2015.

[7] D. Krathwohl, "A revision of Bloom's taxonomy: An overview," Theory into Practice, vol. 4, no. 41, pp. 212-218, 2002.

[8] C. Cheong, V. Bruno, F. Cheong, "Designing a Mobile-app-based Collaborative Learning System," Journal of Information Technology Education: Innovations in Practice. vol. 11, pp. 97-119, 2012

[9] J. Anacleto. "A Teoria Instrucional de Robert Gagné," http://www2.dc.ufscar.br/ junia/teoria_gagne.htm

[10] M. Román-González, J. Pérez-González, C. Jiménez-Fernández, “Test de pensamiento computacional: diseño y psicometría general," III Congreso Internacional sobre Aprendizaje, Innovación y Competitividad (CINAIC 2015), Madrid, España.

[11] F. Coffield, D. Moseley, E. Hall, K. Ecclestone, "Learning styles and pedagogy in post-16 learning: A systematic and critical review," London: Learning and Skills Research Centre, 2004.

[12] R. Felder, L. Silverman, "Learning and Teaching Styles in Engeneering Education," Engr. Education, vol 7, no. 78, 1988, pp. 674-681.

[13] N. Fleming, C. Mills, "Not Another Inventory, Rather a Catalyst for Reflection," 1992.

[14] T. Hawk, A. Shah, "Using learning style instruments to enhance student learning," Decision Sciences Journal of Innovative Education, vol. 5, no. 1, 2007, pp. 1-19.

[15] D. Remenyi, A. Money, "Research Supervision for Supervisors and their Students," Academic Conferences Limited, Curtis Farm, Kidmore End, 2004.

[16] I-TECH, "Technical Implementation Guide. Guidelines for Pre- and PostTesting". University of Washington. Seattle, Washington. USA. 2008.

[17] F. Moreira, M. J. Ferreira, "Profile-oriented algorithms teaching: a proposed methodology to elementary school," In Proceedings of the 7th International Conference on Education and New Learning Technologies, Barcelona, pp. 0309-0317. 2015

[18] A. Manso, C. Marques, P. Dias, "Portugol IDE v3.x- A new environment to teach and learn computer programming," Education Engineering (EDUCON), IEEE, 2010.

[19] M. Resnick, B. Silverman, Y. Kafai, J. Maloney, A. Monroy-Hernández, N. Rusk, J. Silver, "Scratch: Programming for all," Communications of the ACM, 52(11), 60. 2009.

[20] D. Fonseca, E. Redondo, S. Villagrasa, "Mixed-methods research: A new approach to evaluating the motivation and satisfaction of university students using advanced visual technologies," Universal Access in the Information Society, UAIS, 2014, DOI: 10.1007/s10209-014-0361-4

[21] D. Fonseca, E. Redondo, F. Valls, S. Villagrasa, "Technological adaptation of the student to the educational density of the course. A case study: 3D Architectural Visualization," Computers in Human Behavior, 2016, DOI: $10.1016 /$ j.chb.2016.05.048 